\title{
Understanding parent concerns about children's diet, activity and weight status: an important step towards effective obesity prevention interventions
}

\author{
Amy Slater, Jane Bowen, Nadia Corsini*, Claire Gardner, Rebecca Golley and \\ Manny Noakes \\ CSIRO Food and Nutritional Science, PO Box 10041, Adelaide BC, SA 5000, Australia
}

Submitted 26 June 2009: Accepted 22 October 2009: First published online 27 November 2009

\begin{abstract}
Objective: To identify parents' concerns and attitudes towards children's diets, activity habits and weight status.

Design: Computer-assisted telephone interviewing administration of a 37-item survey. Data were weighted for parental education level. Descriptive results are presented, and comparisons are made by the age, gender and parental characteristics of the child.

Setting: Online research panel of Australian parents.

Subjects: A total of 1202 randomly selected parents of children aged 2-16 years, broadly representative of the Australian population.

Results: Parents were concerned about their child's education (reported by $35 \%$ of respondents), child's health and well-being (25\%), and violence, drugs and alcohol (20\%). Concern about nutrition was indicated by $14 \%$ of respondents and concern about fitness/exercise was indicated by $3 \%$ of the sample. Factors perceived as making a healthy diet difficult to achieve for their child were child resistance (89\%), the availability of healthy food (72\%), a busy lifestyle $(67 \%)$ and the influence of food advertising (63\%). Ninety-two per cent of parents thought that it was realistic for their child to be active for at least $1 \mathrm{~h} / \mathrm{d}$, with $75 \%$ of parents feeling that it was realistic for their child to have less than $2 \mathrm{~h}$ recreational screen time per d. Despite this, common barriers to achieving the activity guidelines were lack of time, weather and keeping children occupied.

Conclusions: Insights into parental concerns from the current study may be useful in guiding development of interventions to improve children's nutrition and physical activity habits by framing messages in a way that are most likely to resonate with parents.
\end{abstract}

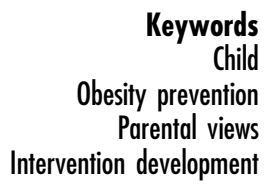

Childhood obesity that has increased dramatically globally ${ }^{(1)}$ is linked to many negative health consequences ${ }^{(2)}$. Negative psychological outcomes, including negative body image and low self-esteem, are also common as are reduced quality of life and employment prospects ${ }^{(3,4)}$. While physiological factors may predispose some children to obesity, environmental factors are also relevant. Understanding environmental influencers of children's eating and activity patterns is important in developing effective obesity prevention and management interventions.

Parents are likely to be the most important influence in determining children's nutrition and activity environment and habits ${ }^{(5)}$. Golan and Crow ${ }^{(6)}$ argue that parents should be viewed as the key players and the central agents for change in the promotion of eating and activity habits. Successful engagement and involvement of parents is crucial in obtaining favourable outcomes from interventions aimed at maintaining a healthy weight status in children. However, information about parental attitudes and beliefs on this topic is scarce, and obesity prevention and treatment has largely overlooked the views of potential participants $^{(7)}$.

In Australia, studies have investigated parents' perceptions about childhood overweight and obesity and perceived barriers to healthy eating in preschoolers ${ }^{(8)}$, parental perception of influences on food choices of 5-6-year-olds ${ }^{(9)}$ and attitudes to physical activity in preschoolers ${ }^{(10)}$. Canadian and British research also provides insights on parental attitudes and perceived barriers to physical activity in preschoolers ${ }^{(11)}$, attitudes to screenviewing behaviours in preschoolers ${ }^{(12)}$ and attitudes to both eating and exercise in 7-12-year-olds ${ }^{(13)}$. Screen-viewing 
attitudes have also been investigated in American parents of 6-13-year-old children ${ }^{(14)}$. Much of the previous research is qualitative in nature, using focus group methodology with discrete age populations and often focusing on either diet or activity. While the research provides insights into parents' perceptions of the barriers to healthy lifestyle behaviours in their children, it is not known how parents prioritise healthy eating and physical activity among other concerns about their children's well-being.

The current study investigates how Australian parents prioritise healthy eating and activity, their attitudes and concerns about children's diet, activity levels and weight status across different stages of childhood.

\section{Methods}

\section{Sample and procedure}

The survey was reviewed by the CSIRO Human Research Ethics Committee. Data were collected by an independent market research company in December 2007 using computer-assisted telephone interviewing technology. The sample was drawn from an online consumer research panel (>100000 participants), representative of the Australian 'internet population'. Panel members are offered incentives for participation. Child's age, household income and postal code (metropolitan and non-metropolitan) were used to select a random sample of panellists with children between 2 and 16 years who were sent an e-mail informing them of the study. Of the 5244 selected, 1413 could not be contacted, and 1997 did not qualify for the study (e.g. unavailable during the survey time). Of the remaining 1834 possible panellists, 632 declined to participate, with 1202 parents completing the interview (65.5\% response rate).

Respondents were asked to answer the survey questions based on one child. Quotas for age and gender of the child were used to obtain an equal number of responses about male and female children in the age groups: 2-4, 5-6, 7-8, 9-10, 11-12, 13-14 and 15-16 years. Respondents were those with primary knowledge about their child's food habits, meal preparation and daily routines. Seventy-five per cent of the sample were female, $72 \%$ of the sample were aged in their thirties or forties, and $92 \%$ reported their marital status as married or living in a de facto relationship. The sample was considered representative of the Australian population apart from parental educational attainment due to an overrepresentation of parents with tertiary education.

\section{Measures}

A 37-item interview instrument was developed that focused on Australian parents' concerns and attitudes about their children's eating habits, physical activity patterns, sedentary behaviours and weight status. The instrument included closed (twenty-four items) and open (thirteen items) questions. Multiple responses were accepted for the open-ended questions that were recorded verbatim and coded against a predefined coding scheme.

\section{General concerns}

Before asking any questions about eating, activity or weight status, parents were asked a broad, open-ended question about their general concerns: 'As a parent, what are the things that you are most concerned about at the moment?' Multiple responses were permitted.

\section{Relative and specific concern about child's diet}

Relative levels of concern were measured by asking There is no doubt a long list of things that may be important to you about your child's overall well-being. If you compare the extent to which you are concerned about what your child eats and drinks with these other concerns, where would you place it in the list?' Response options were 'I would place what my child eats and drinks at the very top of the list; towards the top of the list; around the middle of the list; towards the bottom of the list; and at the very bottom of the list'. Specific concern was measured by asking Do you have any concerns, even if only mild concerns, about what your child currently eats or drinks?' If the parent indicated 'yes', they were asked to specify their concerns. Multiple responses were permitted.

\section{Concern about child's level of physical activity}

The same questions that were asked about concerns about child's diet were asked to obtain an indication of concern about child's level of physical activity.

\section{Concern about recreational screen time}

Parents were asked whether they had any concerns about their child's amount of recreational screen time (defined as time spent watching TV, playing computer games and surfing the net for entertainment purposes, and did not include computer time spent doing homework). As for the questions about concern about diet and physical activity, if the parents indicated that they had some concern, they were asked to specify their concerns.

\section{Child's weight status - parental perceptions and methods of determining}

Parents were asked to specify whether they considered their child to be underweight, normal weight, somewhat overweight or very overweight. To gain an understanding of the methods that the parents were using to inform their perceptions, they were asked 'How do you decide if your child is a healthy weight?' Multiple responses were permitted. 
Activity and screen time-guidelines and barriers

Parents were asked whether they thought it was realistic for their child to have less than $2 \mathrm{~h}$ recreational screen time on most days, and similarly whether they thought it was realistic for their child to be physically active for at least $1 \mathrm{~h}$ every day. For both issues, participants were asked to specify factors that they believed could make it difficult to achieve these recommendations.

\section{Barriers to child eating a bealthy diet}

Parents were presented with a list of possible factors that could make it difficult for their child to eat a healthy diet. For each factor, parents were asked to indicate whether they believed this makes it very difficult (for their child to eat a healthy diet), makes it a little difficult or does not make it difficult at all.

\section{Attitudes to diet and physical activity}

Parents were presented with a number of statements about children's eating and activity behaviours. Example items include 'It's okay for children to have treat foods every day'; 'There is little point in offering foods that my child has previously rejected'; 'Children get enough physical activity through school or childcare'; and 'Physical activity can help children to sleep better'. Participants indicated their level of agreement to each statement using the response options strongly agree, agree, disagree, strongly disagree or don't know.

\section{Analyses}

Sample characteristics were compared with the relevant 2001 ABS Census of Population and Housing data. Comparing sample data grouped by those with tertiary education and those without tertiary education, there was an overrepresentation of the former in our sample $(53 \cdot 8-40 \cdot 5 \%)$. To correct, a weight of 0.75260584 and $1 \cdot 29306333$ was applied to respondents with tertiary education and parents without tertiary education, respectively. Weighted data were used for the present analyses. Results are presented as proportion of responses with percentages reported for ease of interpretation. Statistical analyses were undertaken to compare the results with respect to the age and gender of the children and the characteristics of the parents. Specifically: for categorical data, a $\chi^{2}$ test (Fischer's exact test) was used; for ordinal data, Kendal's tau-b was used. Significance was set at $P<0 \cdot 05$.

\section{Results}

\section{What are parent's general concerns?}

Table 1 displays the most common general concerns for parents by child-school categories. For the whole sample, the most common response was child's education (given by $35 \%$ of respondents). While the concerns are generally similar among parents of the three age groups of children, diet and nutrition is of greater concern to parents of preschool-aged children (mentioned by $21 \%$ of parents of preschoolers), than for parents of primary (15\%) and secondary school-aged children (9\%). Parents of the secondary school-aged children had slightly different concerns from the other groups with concerns about violence, drugs and alcohol being their most common response $(38 \%)$. Concerns about peer pressure (12\%) and future job prospects (12\%) were also more common in this group.

\section{Concern about child's diet}

Sixty-nine per cent of parents responded that concern about their child's diet was either at the very top (22\%), or towards the top ( $47 \%$ ) of their list of general concerns (relative concern). Parents of younger children were more likely to place what children eat and drink near the

Table 1 General concerns raised by more than $10 \%$ of respondents for parents of pre, primary and secondary school-aged children

\begin{tabular}{lll}
\hline Preschool & \multicolumn{1}{c}{ Primary school } & \multicolumn{1}{c}{ Secondary school } \\
\hline Child's health and well-being & Child's education & Violence, drugs and alcohol \\
$(35 \%)$ & $(38 \%)$ & $(38 \%)$ \\
Child's education & Child's health and well-being & Child's education \\
$(33 \%)$ & $(25 \%)$ & $(33 \%)$ \\
Diet, food intake, nutrition & Child's safety & Child's health and well-being \\
$(21 \%)$ & $(16 \%)$ & $(17 \%)$ \\
Cost of living, raising child & Diet, food intake, nutrition & Child's safety \\
$(17 \%)$ & $(15 \%)$ & $(14 \%)$ \\
Child's safety & Violence, drugs and alcohol & Peer pressure \\
$(16 \%)$ & $(14 \%)$ & $(12 \%)$ \\
& Cost of living, raising child & Future job prospects \\
& $(11 \%)$ & $(12 \%)$ \\
& & Social/quality of life \\
\hline
\end{tabular}


top, and parents of older children were more likely to place it near the bottom $(P<0 \cdot 001)$.

Fifty-three per cent of parents indicated that they did have some degree of concern about their child's diet (specific concern). For these parents, the most common concern (given by $46 \%$ of concerned parents) was their child eating too much 'junk' food (foods high in fat and sugar).

Table 2 displays the frequencies (and percentages) of common concerns by the child's stage of education. Parents of older children were more likely to be concerned about their child eating too much 'junk' food, whereas concerns about not eating enough food, additives and artificial flavours and 'fussy eating' were more likely to be given by parents of younger children.

\section{Barriers to bealtby eating}

Just under one-third of the sample ( $n$ 379, 31\%) agreed that they sometimes found it difficult to get their child to eat a healthy diet. These parents were read a list of factors that could potentially make it difficult and then asked to rate the impact of this factor (Table 3). The factor that parents were most likely to agree makes it very difficult for their child to eat a healthy diet was resistance from the child, with $89 \%$ of the sample agreeing that this made it either very difficult (43\%) or a little difficult (46\%). Other factors that were perceived as making a healthy diet difficult to achieve were the availability of healthy food (39\% very difficult; $33 \%$ a little difficult), the influence of food advertising (28\% very difficult; $35 \%$ a little difficult) and having a busy lifestyle (25\% very difficult; $42 \%$ a little difficult). Interestingly, knowing what foods to provide or allow and the effort required to provide healthy foods were not perceived as common factors that make achieving a healthy diet difficult. Although parents with lower incomes were more likely to think that the cost $(P<0 \cdot 001)$; their ability to set rules and stick to them $(P=0 \cdot 024)$; not knowing what foods to provide or allow $(P=0 \cdot 016)$; and the effort required to prepare food $(P=0 \cdot 043)$ made it 'very difficult' to get their child to eat a healthy diet.

\section{Relative concern about child's activity level and recreational screen time}

When asked to compare their concerns about their child's activity level with other general concerns, $53 \%$ of parents indicated that concern about their child's activity was either at the very top (13\%) or towards the top (41\%) of their list of concerns. This level of prompted concern about children's physical activity levels was lower than prompted concern about children's dietary intake.

When asked specifically whether they had any concerns about their child's levels of physical activity, $28 \%$ of

Table 2 Parental concerns about child's diet for pre, primary and secondary school-aged children

\begin{tabular}{|c|c|c|c|c|c|c|c|}
\hline \multirow[b]{3}{*}{ Parental concern } & \multicolumn{6}{|c|}{ Child's educational status } & \multirow[b]{3}{*}{$\chi^{2}(2)$} \\
\hline & \multicolumn{2}{|c|}{$\begin{array}{c}\text { Preschool } \\
123\end{array}$} & \multicolumn{2}{|c|}{$\begin{array}{c}\text { Primary school } \\
342\end{array}$} & \multicolumn{2}{|c|}{$\begin{array}{c}\text { Secondary school } \\
178\end{array}$} & \\
\hline & $n$ & $\%$ & $n$ & $\%$ & $n$ & $\%$ & \\
\hline Eats too much junk & 32 & $26 \cdot 2$ & 155 & $45 \cdot 5$ & 106 & $59 \cdot 6$ & $32 \cdot 4^{\star * *}$ \\
\hline Additives, artificial flavours, colours, preservatives & 25 & $20 \cdot 3$ & 52 & $15 \cdot 2$ & 11 & $6 \cdot 2$ & $13 \cdot 75^{\star \star \star}$ \\
\hline Not eating a wide variety of foods & 11 & $9 \cdot 0$ & 31 & $9 \cdot 0$ & 17 & $9 \cdot \overline{5}$ & 0.03 \\
\hline Not enough vegetables & 23 & $18 \cdot 7$ & 50 & $14 \cdot 6$ & 30 & $16 \cdot 9$ & $1 \cdot 25$ \\
\hline Does not eat enough food & 18 & $14 \cdot 8$ & 21 & $6 \cdot 1$ & 13 & $7 \cdot 3$ & $9 \cdot 20^{\star \star}$ \\
\hline Too many sugary drinks & 14 & $11 \cdot 5$ & 43 & $12 \cdot 6$ & 30 & $16 \cdot 9$ & $2 \cdot 36$ \\
\hline Fussy eating & 14 & $11 \cdot 5$ & 15 & $4 \cdot 4$ & 2 & $1 \cdot 1$ & $17 \cdot 19^{\star \star \star}$ \\
\hline
\end{tabular}

Table 3 Parental level of agreement when asked about factors that could make it difficult for child to eat a healthy diet

\begin{tabular}{|c|c|c|c|}
\hline & $\begin{array}{l}\text { Makes it very } \\
\text { difficult (\%) }\end{array}$ & $\begin{array}{c}\text { Makes it a little } \\
\text { difficult }(\%)\end{array}$ & $\begin{array}{l}\text { Does not make it } \\
\text { difficult at all (\%) }\end{array}$ \\
\hline Resistance from my child & 43 & 46 & 11 \\
\hline The availability of healthy food & 39 & 33 & 27 \\
\hline The influence of food advertising & 28 & 35 & 37 \\
\hline A busy lifestyle & 25 & 42 & 34 \\
\hline The high cost of healthy foods & 22 & 28 & 50 \\
\hline The influence of my child's peers & 19 & 30 & 51 \\
\hline Not knowing how to get my child to eat healthy foods & 14 & 36 & 49 \\
\hline My ability to set rules and stick to them & 13 & 37 & 49 \\
\hline The effort required to provide healthy food & 8 & 28 & 64 \\
\hline Not knowing what foods to provide or allow & 7 & 17 & 76 \\
\hline
\end{tabular}


parents indicated some degree of concern. Of those who were concerned, $71 \%$ were concerned that their child is not active enough.

In comparison, many more parents (46\%) expressed some concern about their child's recreational screen time. For $89 \%$ of these parents their concern was about spending too much time engaged in recreational screen time, whereas $11 \%$ expressed concern about content and safety issues.

\section{Guidelines and barriers to being active}

Nearly all parents (92\%) thought that it was realistic to get their child to be physically active for at least $1 \mathrm{~h} / \mathrm{d}$. Despite this, all participants were asked what factors could make meeting this guideline difficult. The two most common responses were lack of time (38\%) and the weather (29\%). A small number of parents (7\%) reported that lack of motivation and resistance from the child would make this difficult.

Parents were somewhat less confident about the screen time recommendations, although three-quarters of the sample thought that it was realistic for their child to have $<2 \mathrm{~h}$ recreational screen time per $\mathrm{d}$. The three most common responses of the things that could make meeting this recommendation difficult were the weather (12\%), keeping children occupied (11\%) and the child's enjoyment of the screen time activities (10\%). Some parents reported that it causes conflict when they try to limit their child's screen time (9\%), and $8 \%$ of parents reported that it is too difficult to monitor screen time.

\section{Attitudes to child's diet and physical activity}

Parental knowledge, attitudes and beliefs about children's diet and physical activity were assessed by asking parents to indicate their level of agreement with a number of statements. These responses are presented in Table 4 .
When examining responses by the age of the child, parents of older children were more likely to agree that their child is not interested in being active than parents of younger children $(P<0 \cdot 001)$. Similarly, parents of older children were more likely to agree that they feel they have no control over the amount of physical activity their child does $(P<0 \cdot 001)$.

\section{Child's weight status}

Table 5 displays the percentage of children classified by their parents as underweight, normal weight, somewhat overweight and very overweight. In the total sample, $78 \%$ of parents classified their children as normal weight, while around $12 \%$ of parents believed their child to be somewhat or very overweight and $10 \%$ of parents believed their child to be underweight. Data from the 2007 Australian National Children's Nutrition and Physical Activity Survey ${ }^{(15)}$ indicate that $23 \%$ of children aged between 2 and 16 years are overweight (17\%) or obese (6\%) and $5 \%$ are underweight.

For the total sample, the pattern of observed parentreported child weight status was different from the child BMI data observed in the 2007 National Nutrition and Physical Activity Survey $\left(\chi^{2}(3)=139 \cdot 18 ; \quad P<0 \cdot 001\right)$. There was a consistent pattern of parental underestimation of their child's weight status.

The pattern of observed parent-reported child weight status was also different from the pattern from the recent national survey for children aged $2-3$ years $\left(\chi^{2}(3)=24 \cdot 96\right.$; $P<0 \cdot 001), 4-8$ years $\left(\chi^{2}(3)=71 \cdot 50 ; P<0 \cdot 001\right), 9-13$ years $\left(\chi^{2}(3)=46 \cdot 51 ; \quad P<0 \cdot 001\right)$ and $14-16\left(\chi^{2}(3)=17 \cdot 43\right.$; $P<0 \cdot 001$ ) (Table 5).

Parents were asked an unprompted question to gauge how they determine their child's weight status. The responses to this question are presented in Table 6. It can be seen that parents are generally using subjective rather than objective approaches to assess their child's weight

Table 4 Parental level of agreement with attitudinal statements about child's eating and activity levels

\begin{tabular}{|c|c|c|c|c|c|}
\hline & $\begin{array}{c}\text { Strongly } \\
\text { disagree (\%) }\end{array}$ & Disagree (\%) & Agree (\%) & $\begin{array}{l}\text { Strongly } \\
\text { agree (\%) }\end{array}$ & $\begin{array}{l}\text { Net agreement } \\
(\%)\end{array}$ \\
\hline It's okay for children to have treat foods every day & 23 & 44 & 29 & 3 & 32 \\
\hline $\begin{array}{l}\text { There is little point in offering foods that my child has } \\
\text { previously rejected }\end{array}$ & 23 & 43 & 21 & 12 & 33 \\
\hline At times, I feel like I have no control over what my child eats & 39 & 34 & 18 & 7 & 25 \\
\hline Physical activity can help children to sleep better & 0 & 2 & 37 & 60 & 97 \\
\hline Physical activity can help children develop good social skills & 0 & 1 & 40 & 57 & 97 \\
\hline $\begin{array}{l}\text { All children will naturally be active without encouragement } \\
\text { from their parents }\end{array}$ & 25 & 50 & 18 & 6 & 24 \\
\hline $\begin{array}{l}\text { Children get enough physical activity through school or } \\
\text { childcare }\end{array}$ & 18 & 55 & 19 & 6 & 25 \\
\hline $\begin{array}{l}\text { My concerns about safety limit the amount of physical activity } \\
\text { that my child does }\end{array}$ & 26 & 48 & 21 & 5 & 26 \\
\hline My child is not interested in being active & 47 & 36 & 11 & 6 & 17 \\
\hline $\begin{array}{l}\text { I feel like I have no control over how much physical activity my } \\
\text { child does }\end{array}$ & 32 & 51 & 12 & 4 & 16 \\
\hline
\end{tabular}


Table 5 Parental perceptions of their child's weight status (as a percentage and frequency) compared with BMI weight status data from 2007 National Nutrition and Physical Activity Survey (in parentheses)

\begin{tabular}{|c|c|c|c|c|}
\hline & Underweight & Normal weight & $\begin{array}{c}\text { Somewhat overweight } \\
\text { (overweight) }\end{array}$ & $\begin{array}{l}\text { Very overweight } \\
\text { (obese) }\end{array}$ \\
\hline \multirow[t]{4}{*}{ Total } & $10 \cdot 1 \%$ & $77.5 \%$ & $11 \cdot 4 \%$ & $1.0 \%$ \\
\hline & 121 & 933 & 137 & 12 \\
\hline & $(5 \cdot 0 \%)$ & $(72 \cdot 0 \%)$ & $(17 \cdot 0 \%)$ & $(6 \cdot 0 \%)$ \\
\hline & $(60)$ & (866) & (205) & $(72)$ \\
\hline \multirow[t]{4}{*}{$2-3$ years } & $7 \cdot 8 \%$ & $90.5 \%$ & $0.9 \%$ & $0.9 \%$ \\
\hline & 9 & 105 & 1 & 1 \\
\hline & $(5 \cdot 0 \%)$ & $(76 \cdot 0 \%)$ & $(16 \cdot 0 \%)$ & $(4 \%)$ \\
\hline & (6) & (88) & (18) & (4) \\
\hline \multirow[t]{4}{*}{$4-8$ years } & $9 \cdot 8 \%$ & $83.5 \%$ & $6 \cdot 3 \%$ & $0.3 \%$ \\
\hline & 39 & 333 & 25 & 1 \\
\hline & $(4 \cdot 0 \%)$ & $(77 \%)$ & $(13 \%)$ & $(6.0 \%)$ \\
\hline & $(16)$ & (306) & (52) & $(24)$ \\
\hline \multirow[t]{4}{*}{$9-13$ years } & $11 \cdot 2 \%$ & $71 \cdot 7 \%$ & $16 \cdot 2 \%$ & $0.9 \%$ \\
\hline & 48 & 306 & 69 & 4 \\
\hline & $(6 \cdot 0 \%)$ & $(67 \cdot 0 \%)$ & $(20 \cdot 0 \%)$ & $(7 \cdot 0 \%)$ \\
\hline & (26) & (286) & (85) & (30) \\
\hline \multirow[t]{4}{*}{$14-16$ years } & $9 \cdot 5 \%$ & $72 \cdot 1 \%$ & $16 \cdot 0 \%$ & $2 \cdot 3 \%$ \\
\hline & 25 & 189 & 42 & 6 \\
\hline & $(5 \cdot 0 \%)$ & $(71 \cdot 0 \%)$ & $(18 \cdot 0 \%)$ & $(6 \cdot 0 \%)$ \\
\hline & (13) & (186) & $(47)$ & (16) \\
\hline
\end{tabular}

Table 6 Methods reported by parents for assessing child's weight status

\begin{tabular}{lc}
\hline & Percent $^{*}$ \\
\hline Look at child's body & 60 \\
Speak to doctor/health professional & 22 \\
Use growth charts/child health books & 11 \\
Calculate BMI/assess weight-to-height ratio & 10 \\
Child's activity levels & 9 \\
Weigh child & 9 \\
Compare to other kids (including siblings) & 6 \\
Child's eating habits & 6 \\
Fit of clothes & 5 \\
\hline
\end{tabular}

${ }^{*} n 1202$.

status. The most common approach was to assess their child's weight status by looking at their body (given by $60 \%$ of respondents).

While the two most common methods remained consistent across child's education status, using visual inspection of their child's body to determine weight status was a strategy reported more by parents of older children (47\% preschool; 60\% primary school; 68\% secondary school), and the strategy of speaking to a doctor/health professional was utilised less as children got older (35\% preschool; $23 \%$ primary school; $13 \%$ secondary school). The pattern of responses across the age groups was different for both the methods of looking at the child's body $\left(\chi^{2}(2)=26 \cdot 30 ; P<0 \cdot 001\right)$ and for speaking to a health professional $\left(\chi^{2}(2)=40 \cdot 06 ; P<0 \cdot 001\right)$. The method of looking at their child's body to determine their weight status was more likely to be utilised by parents of older children. Consulting with a health professional to assess a child's weight status was a strategy more likely to be used by parents of younger children.

\section{Discussion}

The aim of the current study was to understand the concerns, attitudes and beliefs of Australian parents around children's eating, activity and weight in order to better frame intervention messages in a way that are most likely to resonate with parents.

\section{Using parents' concerns to inform practice}

The current study reveals that the most common parental concern is related to their child's education. Concerns about their child's nutrition or activity levels did not feature highly when parents were asked about their general concerns. Not surprisingly, parental concerns differed depending on child's age. Parents of younger children were more likely to express concern about their child's food intake and nutrition, whereas parents of older children were more likely to express concern about violence, drugs and alcohol. Understanding parents' general concerns may be critical to engaging parents in an intervention, and could suggest ways to frame messages. For example, given parents' concern about education, relating the benefits of healthy living to academic achievement may enhance engagement.

Interestingly, although concerns about nutrition did not feature highly when asked their general concerns, when asked directly whether they had any concern about their child's diet more than half of the parents in our sample indicated that they did. From a general health promotion view, this indicates that many parents are likely to be receptive to messages about how to improve their children's eating behaviours. The fact that the nutrition concerns vary depending on the age of the child also 
provides suggestions for health promotion and intervention strategies. Parents of younger children would appear receptive to strategies for tackling 'fussy eating', whereas parents of the secondary school-aged children would appear to benefit from information and strategies about how to reduce the consumption of 'junk' foods.

The most commonly reported barrier to healthy eating was resistance from their child. Very few parents reported that knowing what foods to provide or the effort required to provide healthy foods were barriers. These findings suggest that intervention programmes may be enhanced by prioritising the 'how to prepare' messages and by including child behaviour management components over an emphasis on 'what to provide' information. These findings are consistent with findings with Australian parents of 2-5-year-olds ${ }^{(8)}$ and 5-6-year-olds ${ }^{(16)}$, as well as UK parents of $7-12$-year-olds ${ }^{(13)}$, that support the conclusion that while parents acknowledge their role or responsibilities around providing children with healthy food, support is needed to overcome barriers such as child/family resistance to a healthy diet, use of treats and lack of time/busy lifestyle.

Parental concern about children's activity levels was considerably lower than concern about child nutrition. This discrepancy in concern around children's activity levels compared to children's food intake should be acknowledged by those who design programmes. Ensuring that the nutrition components are emphasised, and perhaps positioned early in any intervention, may enhance the desirability of the programme and the feeling of the parents that their more pressing needs are being addressed. However, given that the recent Australian figures suggest that Australian children have only a $69 \%$ chance of meeting the guidelines for physical activity and $33 \%$ chance of meeting the guidelines for screen time ${ }^{(15)}$, the relatively low level of concern may require confirmation. In addition to this, one-quarter of the sample believed that children will naturally be sufficiently active without any parental encouragement. This finding appears in accordance with a qualitative finding of Hart et $a l .{ }^{(13)}$, who found that parents unanimously accepted responsibility for providing a healthy diet for their children, but responsibility for exercise was less decisively accepted. Parents' roles in fostering their children's activity levels may need to be emphasised. Although nearly all parents thought that it was realistic for their child to meet the recommendations of being physically active for at least $1 \mathrm{~h}$ per $\mathrm{d}$, addressing practical strategies for managing perceived barriers such as lack of time and hot or cold weather may be important.

\section{Assessing knowledge - what do parents already know?}

One-third of parents believed that there is little point in continuing to offer children foods that they have previously rejected. This suggests that many parents are not aware of the benefits of repeated exposure to promote new food acceptance, a potentially important message in intervention strategies. A third of parents believed that it is fine to offer children treat foods every day, a finding consistent with the beliefs of a sample of Australian mothers of preschool-aged children ${ }^{(8)}$.

In addition to this, assessing knowledge might also reveal areas that may not be necessary to include. Here, nearly all parents appeared to be aware of the benefits of physical activity, perhaps suggesting that time and resources may be better spent on educating about other issues. Hart et al. ${ }^{(13)}$ also reported finding generally high knowledge levels among their sample of British parents of varying socio-economic backgrounds, and suggested that moving towards interventions that aimed to teach behavioural techniques (the 'how' rather than the 'what') may be beneficial.

\section{Parental perceptions of their child's weight status}

Consistent with the findings of earlier studies, the current study found parents consistently under-reporting their child's weight status ${ }^{(16,17)}$ particularly for parents of very young children. Less than $2 \%$ of parents of children aged 2-3 years classified their child as somewhat or very overweight, whereas national survey data indicate that $20 \%$ of $2-3$-year-old children would actually fall in this classification. One possible explanation is that parents of children of this age think their child has 'puppy fat' and is something that they 'will grow out of'. While not examining identification of weight status, Pagnini et al $^{(8)}$ reported that mothers of preschool-aged children were more concerned about their child being underweight than overweight. Child obesity campaigns may need to focus efforts on parents of very young children in order to challenge this pattern of thinking. Alternatively, it may be beneficial to choose issues to which parents are already receptive to promote engagement in behaviours or with messages that support energy balance.

Parents use subjective means to determine their child's weight status. Although parents of babies, and possibly toddlers, may be accustomed with visiting a doctor or other health professional to routinely monitor their child's growth, it seems this practice drops off rapidly for older children. The findings suggest that parents may benefit from education on the importance of objective methods to determine children's weight status and that monitoring should be encouraged to continue beyond the typical period of infancy and very early childhood. Given the complexity associated with measurement and interpretation, it also highlights the need for health professionals to make this a routine part of their health checkup throughout childhood to normalise this practice. 


\section{Study limitations and strengths}

The study findings need to be considered within the limitations of the study methodology. The survey sample is considered representative of the online population that, while reflecting a large proportion of Australian parents, is likely to under-represent more disadvantaged and ethnically diverse populations. The length of the survey and quantitative methodology also limit the depth of responses. Finally, the possibility of participants responding in a socially desirable way must be acknowledged given the potentially sensitive nature of the topics.

The strengths of the current study lay in its large sample size, generalisability to all Australian parents regardless of the age or gender or family circumstances of the child. The study findings add to the body of research on parental perceptions in a novel way by placing nutrition, activity and weight within the broader context of parental concerns. Further research is now warranted to investigate whether framing intervention messages within the context of the parental needs and concerns identified in the current study will enhance intervention efficacy.

\section{Acknowledgements}

Ipsos-Eureka and I-View were commissioned to undertake the research on behalf and under the guidance of CSIRO. The current study was supported by the Australian Commonwealth Government, Department of Health and Ageing as part of the Wellbeing Plan for Children project. R.G. is supported by an NHMRC Public Health Training Award (478115). There are no conflicts of interest to report. A.S., J.B., N.C., C.G. and M.N. conceived of and designed the study. A.S. and Ipsos-Eureka carried out the data analysis. All authors contributed to the interpretation of results and to the development of the manuscript.

\section{References}

1. Lobstein T, Baur L \& Uauy R (2004) Obesity in children and young people: a crisis in public health. Obes Rev 5, Suppl. $1,4-85$.

2. Daniels SR (2006) The consequences of childhood overweight and obesity. Future Child 16, 47-67.
3. Braet C, Mervielde I \& Vandereycken W (1997) Psychological aspects of childhood obesity: a controlled study in a clinical and nonclinical sample. J Pediatr Psychol 22, 59-71.

4. Williams J, Wake M, Hesketh K et al. (2005) Health-related quality of life of overweight and obese children. JAMA 293, $70-76$.

5. Davison KK \& Campbell KJ (2005) Opportunities to prevent obesity in children within families: an ecological approach. In Obesity Prevention and Public Health, pp. 207-230. [DA Crawford and RW Jeffery, editors]. New York: Oxford University Press.

6. Golan M \& Crow S (2004) Targeting parents exclusively in the treatment of childhood obesity: long-term results. Obes Res 12, 357-361.

7. Hesketh K, Waters E, Green J et al. (2005) Healthy eating, activity and obesity prevention: a qualitative study of parent and child perceptions in Australia. Health Promot Int 20, 19-26.

8. Pagnini DL, Wilkenfeld R, King LA et al. (2007) Mothers of pre-school children talk about childhood overweight and obesity: the weight of opinion study. I Paediatr Child Health 43, 806-810.

9. Campbell KJ, Crawford DA \& Ball K (2006) Family food environment and dietary behaviors likely to promote fatness in 5-6 year-old children. Int J Obes (Lond) 30, 1272-1280.

10. Dwyer GM, Higgs J, Hardy LL et al. (2008) What do parents and preschool staff tell us about young children's physical activity: a qualitative study. Int J Behav Nutr Phys Act 5, 66 .

11. Irwin JD, He M, Sangster Bouck LM et al. (2005) Preschoolers' physical activity behaviours - parents' perspectives. Can J Public Health 96, 299-303.

12. He M, Irwin JD, Sangster Bouck LM et al. (2005) Screenviewing behaviors among preschoolers - parents' perceptions. Am J Prevent Med 29, 120-125.

13. Hart KH, Herriot A, Bishop JA et al. (2003) Promoting healthy diet and exercise patterns amongst primary school children: a qualitative investigation of parental perspectives. J Hum Nutr Diet 16, 89-96.

14. Jordan AB, Hersey JC, McDivitt JA et al. (2006) Reducing children's television-viewing time: a qualitative study of parents and their children. Pediatrics 118, e1303-e1310.

15. DoHa (2008) 2007 Australian National Nutrition and Physical Activity Survey - Main Findings. Canberra: Commonwealth Scientific and Industrial Research Organisation (CSIRO) and the University of South Australia.

16. Campbell MW, Williams J, Hampton A et al. (2006) Maternal concern and perceptions of overweight in Australian preschool-aged children. Med J Aust 184, 274-277.

17. Parry LL, Netuveli G, Parry J et al. (2008) A systematic review of parental perception of overweight status in children. J Ambul Care Manage 31, 253-268. 